\title{
THE REPORT OF THE INTER-DEPARTMENTAL COMMITTEE ON PHYSICAL DEGENERATION.
}

By Str LAUDER BRUNTON, M.D., LL.D., D.Sc, F.R.C.P., F.R.S.

Mr. President and Gentlemen, - I thank you for the honour you have done me in asking me to open the discussion on the report of the Physical Deterioration Committee. There is no more fitting assembly in which to do it than this, because the evils which this report acknowledges must be in great part remedied by the efforts of two bodies, namely Medical Officers of Health and school teachers, and the combined efforts of these two will probably do more for the physical welfare of the people than those of any other section or sections of the community. This committee owed its existence to an admirable memorandum addressed to the War Office by Sir William Taylor, Director-General of the Army Medical Service, in April, 1903. In this memorandum he drew attention to Sir Frederick Maurice's statement that two out of every five would-be recruits were unfit for service at the end of two years, and showed from the recruiting tables that from 1893 to $1902,34 \cdot 6$ per cent were rejected on inspection, and 3 per cent more were either rejected within three months or discharged as invalids, before they had completed two years' service. This brings the total of unfit within two years up to $37 \cdot 6$ per cent, which is a little less than two out of every five, or the 40 per cent which Sir Frederick Maurice had stated it to be. In consequence of this an Inter-Departmental Committee was appointed, and after eleven months of hard work presented the report which we are now about to discuss.

The first thing that strikes one is that the name of the Committee was an unfortunate one. As Sir William Taylor very clearly pointed out, the important question was not that of deterioration as compared with past time, but that of physical inefficiency in the present. Yet in spite of his remonstrance the Committee in their conclusions bave given much more prominence to the question of deterioration than that of inefficiency, and instead of recognizing the invaluable services which Sir Frederick Maurice and Sir William Taylor have rendered to the community by drawing attention to this inefficiency, they have rather slighted them by saying in their first conclusion that "the Committee hope that the facts and opinions that have been collected will have their effect in allaying the apprehension of those, who, as it appears, on insufficient grounds, have made up their minds that progressive deterioration is to be found among the people generally." After this soothing statement it is rather curious to find that the 
Committee state that in order that " the present 'acknowledged evils' may be removed, complacent optimism and administrative indifference must be attacked and overcome." But whatever fault may be found with the conclusions of the Committee there can be no doubt whatever as to the enormous value of the information contained in the body of the report and in the evidence that they have collected. In regard to the question whether the whole population or even those composing certain strata have undergone deterioration, Sir William Taylor, in a second memorandum of November, 1903, pointed out that there are no reliable data for the past physical condition of the people, so that it is impossible to form any satisfactory comparison with the present, and to ascertain with any certainty whether deterioration is going on or not.* To this conclusion the Committee have also come (Par. 67).

In order that data shall be afforded for future comparison they recommend that a physical census of the people shall be taken, beginning with the children in schools and factories and extending it gradually over the population at large ( $\mathrm{Par}$. 423). The apparent decrease in the physique of recruits they consider to be due not to any actual deterioration of the population, but to the recruits having been drawn from a stratum of the people poorer and physically weaker than that which formerly supplied them (Par. 30 of the Report). The conditions giving rise to this physical inefficiency have been very thoroughly investigated by the Committee, and it appears that, excepting where parents are affected by syphilis or drunkenness, the child inherits at birth a good physique, and if properly cared for in infancy and childhood it may grow up strong and healthy, although its father and mother may be physically weak from bad surroundings (Par. 247). Unfortunately the chances of a child born under such circumstances receiving proper care are small, for the weakness of the mother in a very large number of cases renders her unable to suckle. her child, and the food that is given, either from ignorance, carelessness or poverty, is quite unsuitable, so that the "sacrifice of infant life is enormous" (Par. 277). In addition to this census periodical measurements of children and young persons in factories should be taken. For this purpose, school teachers, factory surgeons, and a small staff of professional surveyors ( $\mathrm{Par} .423$ ), may be able to superintend the process, but they cannot instruct the teachers, and the most likely person to be called upon to give instruction, will, I think, be the Medical Officer of Health. The medical examination of school children, which should not only be complete, but periodical, underlies, as the Committee very truly says, all schemes for improvement in school training (Par. 320). It is only by such examination

\footnotetext{
* Report, p. 100.
} 
that we can learn what the capabilities of a child are, and what amount of work, mental and physical, may reasonably be expected from it, and it is only by repeated examinations that we can ascertain what effect the school work and the school exercises are having upon it. The system of examination for mental work is already in full swing. and we now want that system extended to physical conditions. By such examination it will be possible to put clever and weak-minded children into different classes, to place the physically strong, the physically weak, and those suffering from unsuspected cardiac or other disease, in their proper groups, and by adapting the mental and physical training to each we shall get the maximum of good and the minimum of harm. All this will take time, it will take skill, it will take attention and care, and who is to do it? Such inspection is no doubt a branch of public health, but can medical officers undertake it in addition to their other duties, remembering that it is not only for once that this has to be done, but that it must be periodical ? Such inspection I think may well avoid a great deal of injustice. I remember when at school seeing a boy caned every day for not knowing his lessons, and great was his delight as he came to school one morning saying that he knew them perfectly. Poor boy! he was caned all the same, and $I$ am quite convinced now that it was neither indifference, carelessness, nor stupidity on his part, but simply defective vision, so that he did not see what was written upon the blackboard; and so, however perfectly he had prepared his lessons beforehand, he was unable to do what the masters desired. A pair of glasses I feel sure would have saved him a daily caning, and would have saved many another child from headaches almost as frequent and perhaps even more painful. And what an amount of pain might be saved to children by periodical examination of their teeth, by the judicious application of a little bicarbonate of soda to remove actual aching, by extraction if necessary, and by the regular use of a piece of soft wood every night as a toothbrush. In many cases, no doubt, timely stopping of the teeth might prevent further decay, but here again the question arises, who is to do it? At the same time that the teeth are inspected the medical officer would see the state of the tongue, and with the assistance of a question or two might find out facts of importance in regard to the child's digestion and the suitability of the food it was having. By examination of the ears the child might not only be saved much pain, but much danger, and by timely care mastoid abscesses or even meningitis might be prevented. Such examination too, in many cases, might show the advisability of a child's exemption from school for a while, and the risks it would otherwise run from exposure to cold, etc., might be avoided. For sometimes in going to school the child 
may get its shoes, stockings, and clothes wet, and having no change at school may sit there for hours with a chance of greatly aggravating any mischief in the ears or elsewhere, or even bringing on disease when the child was previously healthy. It is very difficult to see how such risks can be completely prevented, but at any rate inspection would greatly lessen the dangers to which they would otherwise give rise, and the proper warming of schools suggested in recommendation 34 of the Committee's report requires special attention.

All the recommendations of the Committee must, I think, have the approbation of all medical men, and one of the questions for this Society to discuss is, how they had best be carried out, and what part Medical Officers of Health may be expected to take in doing so. In all probability judicious physical training will not only aid the growth of a child, but will make it more healthy generally, and give it more power to resist disease. Judicious physical training necessitates, as I have already said, a preliminary medical examination. A few months ago I went to Philadelphia, and was told that all the undergraduates of the University of Pennsylvania are obliged to go in for a course of physical training. Before doing so they are inspected medically and their weak points ascertained. The exercises are so adjusted as to strengthen the weak points and bring the men up as far as possible to an all-round standard of strength. Something of the same sort would be done by medical inspection, and the Committee are no doubt right in advising that regular gymnastic exercises, as well as games, should be included in the programme (Par. 308). The provision for proper accommodation for exercise in bad weather, and for playgrounds in good weather, would be one of the duties of the local authorities, and it will fall to the local Medical Officer of Health to see that it is carried out rightly. The feeding of school children is another question of the utmost importance, and the opinion of the Medical Officer of Health would in all probability be required, both as to what children are to be fed, and how they are to be fed (Par. 358-365 and Rec. 42, p. 91). If I may venture upon a suggestion, it seems to me that a regular school kitchen might be attached to every school, and in this meals might be prepared, and such children as could pay for them might buy, and those who could not pay might be provided for either by voluntary subscription or by the rates. The large demand for food which this would bring about would give ample opportunity for the girls attending the schools to learn cookery, and the instruction which they would receive in the art of preparing palatable meals at a chea $p$ rate would not only be useful to the children themselves in their own future life, but it would 
probably re-act upon their mothers at home, and might induce them to learn a little more about the way of preparing food. At the same time that the children are learning how to cook food, they might receive instruction as to the comparative values of the different kinds of food, and the best way of spending money so as to get the utmost value for it. Such school kitchens might perhaps sometimes give cooking lessons to adults, and occasional lectures on food and food-values might perhaps be given to them, and here also the services of the Medical Officer of Health will probably be required to give them instruction, or to secure those who are capable of doing so. Schools should thus become great object lessons to children in ventilation, exercise and food; but in addition to this there should be systematic instruction in the general principles of hygiene, the evils of alcohol, the disadvantages of early smoking, and the injury that may be done by excessive tea-drinking. In this way we may hope that the rising generation will know a good deal more about the laws of health than their predecessors; but the mothers and fathers may also be instructed by occasional lectures. A great deal may be done by lady visitors who will visit the homes and see that the general principles in lectures, or at school, are actually being put into practice. It will I think not be difficult to get such visitors full of enthusiasm, energy, kindness, and sympathy; but what they will need will be information and direction, and here the Medical Officer of Health may work with them and through them to the great advantage of all concerned. We have been talking of the feeding of children and adults, but now we come to one of the most important questions of all, the feeding of infants. There can be no doubt that if mothers were not to work for at least one month before and after delivery, it would be much better for their progeny, but the difficulties of enacting a law to this effect are great, and might be productive of much hardship. We may hope to amend things by and by, but as things are now we must accept the fact that a great many mothers for one reason or another are unable to suckle their children, and the children will be fed artificially. If the child is to be satisfactorily reared, milk in some form is indispensable. Some infants may thrive even upon condensed milk and cereal foods, but for the great majority fresh milk is needed, and the difficulty of getting milk, clean, fresh and unadulterated in towns is considerable, especially for those belonging to the poorest of the population. It has been suggested that the municipalities should provide millk depots. For my own part I am inclined to think that instead of doing this directly the municipalities would do better to arrange with the large dairy companies in whose hands the chief supply at present lies, and oblige them under a heavy penalty to supply milk which will conform to the 
requirements laid down by the municipality. I believe, however, I am right in stating that the President of your Society, who probably knows more about this than any one else, is at present engaged in drawing up a scheme for the proper supply of pure milk to towns. As I know from sad experience in my own family, there are some children whom it is impossible to bring up on ordinary cow's milk, however pure it may be, or however diluted; and I believe that if such children are to be kept alive it is necessary to provide them with milk in which the various ingredients are properly adjusted in accordance with the child's needs according to a doctor's direction in a laboratory, just as the ingredients of a doctor's prescription are made up for him by a chemist. I think that the proportion of such children is quite a small one, but that they do exist I am certain, and without provision being made for them they will certainly die. Such provision I think might be made by establishing small hospitals scattered throughout large towns where the worst cases might be treated indoors, and the less serious ones might perhaps be treated as outdoor patients, while each such hospital, as well as the out-patient department of general hospitals, should be a focus for disseminating information regarding infant feeding by means of verbal instruction and printed leaflets, whilst lady visitors, by visiting the parents at home, might see that the instructions were properly carried out; these visitors having, as I have already said, themselves: received instruction from the Medical Officers of Health.

The last, but not the least; question which I shall touch upon is that of house accommodation. Over-crowding, with its attendant evils of uncleanliness, foul air, and bad sanitation, stands out prominently in the opinion of the Committee as prejudicial to the health of the people (Par. 82). Over-crowding is almost certain to arise if people will flock in from the country to the towns, and that they do so in great numbers there is no doubt, for to every one who lived in a town in 1851 three do so now (Par. 80). This may perhaps be diminished by making country life more attractive, country homes more comfortable, the food in them more appetising, the cottages more attractive, and by providing some sort of amusement in country villages or country districts for men and women after the day's work is done. Much no doubt should be done in regard to country cottages, and building bye-laws require to be carefully supervised lest they do harm instead of good. I may be quite mistaken, but it has occurred to me that one of the forces that is driving people from the country to the towns is the difficulty of getting cottage accommodation, a difficulty which to some extent is due to the combined action of the law of entail, and to the change in agricultural conditions brought about by ocean steamers and cold 
storage. On account of the cheap freights, wheat and butcher meat can be brought from America and Australia with great ease, and sold in this country at such rates as to keep down the price of home-grown wheat and home-grown meat. The depression of the price of meat of course affects also the value of root crops and feeding stuffs, and in this way the value of land for agricultural purposes has become enormously depreciated. Rents have consequently gone down, and many men who own enormous estates have their incomes from the land so much reduced that, burdened as they often are with the payment of jointures or of mortgages, they are in reality so poor that they cannot afford to build new houses on their estates. This difficulty might possibly be met in two ways, first by making it easier to break the entail and sell part of the heavily burdened properties so as to relieve the remainder, or else by some provision by which joint stock companies should be allowed for a perfectly nominal ground rent to build cottages on such estates and draw the rents directly from the tenants. Companies building cottages in very large numbers could probably put them up more cheaply than others, and one of the great causes which is driving the country population into the towns would thus be done away with. In towns the effect of over-crowding in raising the death-rate came out very prominently in the evidence before the Committee (Par. 86), and they think that in order to lessen the evils the local authority should, with a view of settling a term to these evils, exercise their power to treat any house, or any part of a house, so over-crowded as to be dangerous or injurious to the health of the inmates, as a nuisance, and for the abatement of the same notify that at a given date no one-room, or two-room, or three-room tenements will be permitted to contain more than two, four, or six persons respectively (Par. 87). The slums must go, and in their removal, as one witness very truly said, everything must depend on the powers of the Medical Officer of Health, on the keenness with which he exercises these powers, and in the way in which he is supported (Hawke's Par. 13011). As things are at present, the Medical Officer of Health, by the very thoroughness with which he discharges his duty, may incur the dislike or resentment of some of the local authorities by whom he has been appointed, and they will in consequence try to get him discharged, if they can, sometimes unfortunately with success (Par. 13511). In Par. 118 and Rec. 9, p. 86 of the report the Committee makes a proposal which seems to be a good one, that the Medical Officer of Health should have security of tenure and not hold his office at the good will of the local authority. Behind the Medical Officers of Health stand at present the Local Government Board, but the offices of this Board are so manifold 
that it is impossible for it to discharge them all properly, and perhaps the best thing for the country would be to have a Board of Health. There does not seem to be at present very much chance of such a Board being appointed, and in place of it the Committee propose an advisory Council which should represent the Department of State within whose province questions touching the physical welfare of the people fall, with the addition of members of the community by the medical corporation and others, whose duty it should be to receive and apply the information obtained from a bureau of the Local Government Board with the whole weight of Government authority and scientific prestige behind them. It would be their function to advise the Government on all legislative and administrative points in respect of which State interference in health matters was expedient, consider and report upon all problems of public health, and guide the action of representatives in this country in foreign congresses of public health (Par. 64, 124, 302, and p. 85).

Failing a Board of Health such an advisory Council would in all probability be a great service, and the Society that I am now addressing may do a great deal to insure that these recommendations are carried out, and also to insure that the advisory council is constituted in the right way and with proper powers. The question of public health is a very complex one, and however much those who take it up are interested in it, however hard the various associations which are working for its attainment may toil, it is hardly possible for them to succeed if they work singly. In order that the common end may be successfully attained they must all work together, and it is with the object of attaining co-ordinate action that it has been proposed to found a National League for Physical Education and Improvement. The object of this League, as stated in the draft scheme of which copies have been supplied to you, has for its object not to displace any of the agencies at present at work, but to make them known to one another, to ascertain how best their work can be supplemented where it is deficient, and to extend the benefits of physical education throughout the whole country. In every parish the squire, the parson, the minister, the schoolmaster, and the benevolent woman, and in towns the mayors, or provosts and corporations, should be induced to take part in the organization for carrying out all the means of physical improvement which have been touched upon in this address. This league has not been brought formally before the public, because it has been thought better to have the scheme thoroughly worked out before this was done, but men of all classes and in every part of the country have already agreed to support it. It was felt that as the purposes of the League are closely connected with medicine, it was 
better to have it backed by medical men before other classes of the community were asked to join, because most of them are less able to judge of its merits or demerits than medical men, and they will consequently be led to decide their action in regard to it chiefly by the leaders of the medical profession. At present, with the exception of a few men who have been very active in promoting the league, either in London or the provinces, only men holding Court appointments or official positions as heads of medical corporations have been asked to join. Amongst those who have consented to act as Vice-Presidents, I am glad to say is the President of your own Society, and I trust that as soon as the league is publicly brought forward, not only every Medical Officer of Health and every school teacher will join it, but that every man and woman in the country may become associated with it, and that every child may derive benefit from it. Although the Committee in its conclusions say that in carrying out their recommendations for the rectification of acknowledged evils they do not rely upon any large measure of legislative assistance, yet the proposed League, by numbering amongst its members all the men and women who know what is necessary, and many Members of both Houses of Parliament who will act upon such knowledge, may bring about legislative improvement such as no single body at present could hope to effect, at least in a moderate time. Through it the Medical Officers of Health may be able to bring about quickly much needed changes which they see to be necessary, and if they and the school teachers combine with others, who, like them, have the welfare of the nation at heart, they will be able to carry out thoroughly the measures which the Committee advised in their third resolution, namely "complacent optimism and administrative indifference must be attacked and overcome, and a large-hearted sentiment of public interest take the place of timorons counsels and sectional prejudice." In conclusion, gentlemen, let me again thank you for the honour you have done me in letting me open the discussion, I beg you to pardon me for the very imperfect way in which I have been able to fulfil the task, and ask your approval and assistance for the proposed National League for Physical Education and Improvement, a league by which $I$ believe that the recommendations of the Report of the Inter-Departmental Committee on Physical Deterioration may be carried into effect, and the welfare of the nation, which both you and I desire so greatly, may be secured.

\section{PROPOSED NATIONAL LEAGUE FOR PHYSICAL EDUCATION AND IMPROVEMENT.}

ObJects of the LEAgue.

It is obvious that as the causes of physical imperfection are so numerous and act upon such numbers of people and over such a wide area, the 
means to combat these causes must also be various in kind and must act over the whole length and breadth of the country.

A great number of agencies are already at work giving instruction in the rules of health, in housekeeping, in cooking, and in the feeding of children. Others are trying to lessen the consumption of alcohol by supplying nutritious food in its place. Others again are trying to improve the physique of the rising generation by supplying gymnasia in town or country; by organizing associations for physical exercise, such as cricket, football, drill associations, cadet corps, boys' brigades, rifle clubs, volunteer corps, and girls' clubs.

In the social class immediately above the lowest class of the population there are boys and girls whose occupations are sedentary and their wages small. They cannot afford to join tennis, cricket, football, and similar clubs. For these young and growing persons gymnasia and swimming baths should be available at a nominal cost. Already many municipalities are converting the swimming baths used only in the summer months into gymnasia for the winter months.

The numerous associations which are all working for the common object of increasing the physical development and well-being of our population are at present under the disadvantage of not knowing what the others are doing, and of being even unaware of their very existence.

Draft Scheme of the Proposed League.

The object of the proposed Physical Education and Improvement League is not to displace any of the agencies at present at work, but to make them known to one another, to ascertain how their work can best be supplemented where it is deficient, and to extend the benefits of physical training throughout the whole country. The League would thus be subdivided in a two-fold manner, territorially and functionally.

Territorially it would be divided into local branches. In each parish and in each small town there ought to be a branch, and in larger towns several branches, according to the population.

Several branches should become associated into a district, and several districts into a county or borough branch. These might not only co-operate with one another, but also by a healthy rivalry might stimulate one another to active efforts.

Functional division is necessary, because the objects requiring attention are so numerous.

Each branch should furnish instruction to the people on the laws of health generally, to mothers on the care of children, to girls on the methods of cooking and housekeeping. Physical exercises and opportunity for open-air games should be given to both boys and girls; while the natural desire of boys to become volunteers should be encouraged, and drill, rifle, and shooting practice and all sports fostered. In every parish the squire, the parson, the doctor, and the schoolmaster, and in towns the mayors and corporations, should be induced, if possible, to take part in their organization, whilst there should also be a committee of ladies to supervise the instruction of mothers and the care of children. The work to be done in each district would be subdivided, the ladies would undertake the teaching of mothers and the inspection of houses and children, the schoolmaster and mistress would supervise the physical exercises and games of the children, the squire or mayor, or others interested in the subject, would look after the provision for playgrounds, rifle ranges, club rooms and drill halls, and we feel sure that the doctor would give general advice and assistance wherever he could. 
A great deal of work would be done locally by the branches, but it would be necessary to have a central burean to which any branch might apply for any information or help which it required. It would also be part of the work of the League to initiate changes in, or additions to, existing laws, when such changes or additions seemed necessary, and the immense amount of information which would then be at the disposal of the League would render its advice invaluable. Amongst other objects to be aimed at would be the medical inspection of school children.

\section{DISCUSSION.}

SIR JoHN Gorst, M.P., said that although as a matter of fact he had merely come as a listener, he could not refrain from supporting the proposals made by Sir Lauder Brunton, with which he cordially agreed. He greatly rejoiced at the way the movement had been taken up in the country by the medical profession generally. He considered they were the most competent body in the country to deal with it, and if they took it up seriously it could not fail to be a success. For many years, long before this Committee was appointed, all those who were engaged in the work of elementary schools of this country were conscious of the great proportion of children who went to the schools totally unfit to receive the education provided for them. An Act was passed, therefore, controlling the work of school children out of school hours in the endeavour to promote a better condition among children. The proper body to take action in this matter is the educational authority, the local authority, and town councils, who have very wide and general powers, even sufficient power without legislation to do anything to promote the general health of the children. The best thing they and the League could do would be to bring pressure to bear on all local authorities throughout the country to move in the matter at once without waiting for legislation. The first thing to go for is a medical inspection. They might at least get a medical inspection of children when they first went to school, and thus have record kept of the actual condition of the children when they first attend school. By supplementing this with periodical examinations, it should bring home to the educational authority the actual condition of the children they are attempting to instruct. But the inspection would only tell them what the mischief was, and then how were they to cure it? In his opinion by far the best plan was to have a Board of visitors attached to every school. He referred to what had been done in connection with the Tower Street School, in Seven Dials. A voluntary committee of ladies had been formed there six years ago, and the schoolmistress reported to them any instances of ill-nourished or ragged children, or those suffering from any ailment or disability of any kind. The members of that committee then visited the parents, gave advice, and no doubt assistance. In six years the result is that whereas $£ 40$ was spent every winter in feeding children in this school they now only spend $\mathfrak{E} 6$, and the children are better clothed and happier than they were. In fact, the system carried on there is so satisfactory that when the parents remove from the neighbourhood they send their children great distances in order to attend it. He did not think it would be a very costly thing to feed all the children if a proper system of visitation were adopted. The residuum of children whose parents could not afford to feed them would be so small that they might be fed by the public authority. Dr. Eichholtz, an Inspector of the Board of Education, who was before the Committee, said that there were two classes of the children in the very 
poorest districts who stood out in great contrast to the rest, and these two classes were the Jews and Irish. Their children were better fed and healthier than the other classes whete they lived. This has been confirmed by Dr. Hall, of Leeds, an ex-factory surgeon, who devotes himself to an examination of this lrind. He gave the speaker a description of two schools in the very dirtiest parts of Leeds. They were both Board Schools under the local authority. One was frequented almost entirely by Jews and the other by Christian children, and the contrast was marvellous. It was apparent at once on entering the sehools. The parents of the one class were as poor as the other. But with the Jews it is part of their religion to take care of their children; the mothers usually suckle the children, and the fathers make great sacrifices to bring them up, and that, he considered, was the reason they were such a healthy class. He thought that if they organized visiting committees they might bring the Fnglish Christian mothers up to the same level as the Jews and the Irish. He had been travelling about the country a great deal, and found that this question of feeding the children was exciting great interest everywhere, especially amongst the working classes themselves. $\mathrm{He}$ was strongly of opinion that some step should be taken in this direction, and thought that pressure could very easily be brought to bear on Town Councils and Boards of Guardians, as they were elected once a year. He felt sure that the effect of the movement now taking place would be that the local authorities would be stirred up to improve the condition of the children. He was of opinion that they possessed sufficient powers to make a very great change in the condition of the children of the poor without waiting for the very slow progress of legislation in the House of Commons.

Dr. H. Franklin Parsons, speaking in his private capacity as a Member of the Society, and not as an Official of the Local Government Board, said that he had listened with very great interest to Sir Lauder Brunton's paper, which, no doubt, deserved the highest consideration. At the same time he thought a few words of caution were needed. In the first place, he thought they would do harm rather than good by adopting measures which would in any way tend to diminish the sense of individual responsibility. It was the tendency of the present day to assert the people's rights and wishes and pleasures, before their duties, and they ought not to lessen in any way a parent's responsibilities towards his children. Sir John Gorst had given a very good illustration in his description of the two classes, the Jews and the Irish. He personally was afraid that free meals for school children would tend to do harm rather than good, because it would relieve parents from the sense of responsibility, and wages might be lowered, as was the case under the old Poor Law. Secondly, parents would have more money to spend in drink, which is one of the prominent causes of deterioration. He thought that Sir John Gorst's suggestion of visiting committees was a very good one, and reminded them that the system already existed in regard to the boarding out of pauper children. Another way would be through County Medical Officers of Health. Every county ought to appoint a Medical Officer of Health, and as the county is the educational authority, the supervision of the health of the children might well form a part of his duty. He considered that neither the county nor the local Medical Officer of Health could make such a periodical supervision of the children as had been suggested, but they could supervise the work. If the children were periodically weighed and their height measured, and any noticeable defects registered, any one examining the register would see if the children 
were improving, and if not it would be a duty to see what was the matter at home. They must have some regard to the cost of the proceedings they recommended. By putting extra burdens on the community they might be doing more harm in one direction than good in the other. What he wished to say was that by raising the rates it would be a greater burden on the working classes than on any one else.

Miss ANDerson (Home Office), said that she considered it a great honour and privilege to be allowed to address the meeting. Speaking in her private capaeity, she considered that although the lady visitor, the "benevolent woman," was possibly a great asset for public health, she lacked training, and this might be taken up with advantage by the League. Many women had very little opportunity of learning how they could help, and as regards the parents; she thought that their mistakes were more due to ignorance than lack of will. Her own opinion was that girls of all classes in this country, from the lowest to the highest, required longer teaching in order to prepare them for motherhood. It was impossible for them to learn hygiene from English mothers of the present day, they all required teaching. She considered there were two directions in which progress might be made-one an expensive method, by lengthening the education of the girls; the other by recognizing the need of women who could teach, and by giving them a special training. She hoped that eventually the result of the proposed League would enable the mothers to remain at home and tend their children instead of being compelled to go to the factories as at present.

DR. J. C. MCV AIL considered that the Society was immensely indebted to Sir Lauder Brunton for the way in which he had brought forward the question, and it was impossible not to sympathize with the speaker in regard to the title given to it by the Committee. They all knew that there was abundant physical deficiency, but they did not know whether it was greater or less than it was fifty years ago. There was no doubt that the population in towns had greatly increased, but at the same time the death-rate in towns and country districts had fallen immensely. It might be conceivable that the modern sanitary conditions ought to be such as to allow unhealthy people to live a longer life than healthy people fifty years ago. As to the first recommendation, the establishment of anthropometrical measurements, he did not think the Society should push the matter too strongly. Were they likely to get such a thing from a Government which would not grant a quinquennial census or pay for a meteorological observatory on Ben Nevis? That sort of thing might be done in Germany, but he did not think it would be possible in Great Britain. He thought they were just at the beginning of a great advance movement in public health. Up to the present they had been occupied in environment, with the improvement of the environment of the individual. They had made great progress in that direction, and now they were beginning to attack the individual himself. $\mathrm{He}$ thought, however, that the advice tendered by Dr. Franklin Parsons should be borme in mind. They could not make all people equal. What they wanted was to give every child a chance, and for that purpose it was right to go to the individuals and try to find out what defects they had, but there must be as much voluntary organization as possible in the matter. He thought the suggestion of Sir John Gorst with regard to committees connected with every school an admirable one. There would have to be official supervision, but the money should go from the pockets of the benevolent. He called attention to the fact that in connection with the Scottish School Board one authority had recently 
taken two working class dwellings, and had appointed teachers and practical housekeeping for each, so that the children might learn cooking and domestic economy. By this means each girl had several hours trition weekly in such dwellings as she would be likely to eventually occupy in her station of life. With regard to the reference to depreciation of agricultural land, he thought that the new system of vehicular traffic by motor cars would have a beneficial effect on rents, as it would enable large factories to be established in country districts. An attempt is already being made in Glasgow. The University printers have taken their works right out into the suburbs, and have built proper houses for their work people. He considered the appointment of an Advisory Council a very excellent suggestion. Personally, he thought that if one could get at the actual minds of the great public departments they would find that they are thoroughly in sympathy in all these matters, but the mouth of the official is closed. The Advisory Council would at least be able to tell the country what it thought after studying the subject.

Dr. Arthur Newsholme said they were greatly indebted to Sir Lauder Brunton for having been the means of introducing such a valuable discussion. Sir Lauder Brunton's presence there that evening reminded him that he was one of the men who had given the death-blow to polypharmacy. At the present day they appeared to be passing through a polypharmacentical stage of preventive medicine, and a large number of empirical remedies were suggested for present evils. But they had not dug down to the root of all the mischief. The statistical bases on which Sir William Taylor's remarks were based as well as those of Sir F. Maurice, were shown to be entirely untrustworthy, and the army medical statistics were not only misleading but extremely fallacious. He thought, however, they should be grateful to Sir William Taylor and Sir F. Maurice for having initiated an agitation out of which good might come. It seemed to him that Sir Lauder Brunton had really defined three main evils, viz. overcrowding, deficient or improper food, and alcoholism. Here again, in the report of the Committee and elsewhere, they had the same lack of distinction between primary and secondary causes. For instance, overerowding took place either because people were too lazy or indolent to spread themselves, or more frequently because they cannot afford more house room. Fither they cannot afford it or spend their money in other directions, or the rooms cost too much. The building of houses in towns was bound to become dearer and dearer. There is no possibility of cheapening houses, and there is only one way to deal with the matter, and that is by increasing wages, so that people can pay a fair rent. Then as to the question of deficient feeding, a matter which Sir John Gorst had taken up with great skill. Why are the children improperly fed? Either the parent does not earn sufficient or he spends his money in the wrong direction. Therefore in the frst case give him higher wages, but do not supplement his earnings by the State. If he spends his money wrongly, he should be compelled as far as possible to give his money to his family, so that they may be properly housed and fed. Sir John Gorst had said that the residuum of children who required to be fed was a very small one, and might be fed by the local authority. $\mathrm{He}$ considered that Sir John Gorst had thereby given away his case entirely. If the residuum was a small one, why should the State step in ? In his, the speaker's, town (Brighton) they gave away 600 breakfasts every morning.

In many cases they were obliged to decline to give the breakfasts. He agreed, howeyer, that underfed children are totally unfit to receive the 
education that is given to them, but at the same time they are in no worse case than children outside the school. He did not for one moment argue that they should not be fed. Indeed, the small residuum of cases left over they were all most anxious to help, but they must be picked out with the most rigid diserimination. They were all agreed with regard to the committee of visitors recommended by Sir John Gorst. But he, personally, disagreed with Dr. MeVail's contention that it is impossible to have proper anthropometrical observations of the children. $\mathrm{He}$ sonsidered they ought to have them once a year. As to free breakfasts, he thought the working classes would have to give them if they were given. He ventured to think, however, that voluntary organization was not yet exhausted and that there was no need to call in State intervention.

Dr. A. K. Chalmers said he appreciated to the utmost Sir Lauder Brunton's paper. He considered that the inspection of school children had a practical value. For instance, in Glasgow they had been carrying on some investigations which showed that children graded almost definitely to the size of the house they occupied. Further, whatever may be said with regard to feeding the children, they must accept the alternative; either feed them or allow them to grow up in the class of inefficients. Following the London experiment referred to, the Glasgow School Board had taken over a school for little children. The difficulty was to feed them. As they had no fund to meet the cost of food, the ladies who organized the mission called on the parents and said that the children could be educated on condition that the parents paid the expense of food. The actual cost worked out at a trifle over $1 \frac{1}{2} \mathrm{~d}$. per meal. For $9 \frac{1}{2}$. per week the child got food, and after four or six weeks it was apparent to the teachers that the children were physically good. The value of that illustration he thought was that whether the parents have to pay or the State has to pay, the argument in favour of the State paying is the growth of the inefficient. That Jewish children turned out better physically on inspection he understood was the case in all places except Glasgow. He did not think they had a worse type of alien than the Jews in Glasgow. They were not physically better in comparison with the Christian children, and he found that the Jews were very much worse as regards eyesight. In conclusion, he would like to associate himself with everything that had been said in connection with home visitation.

DR. KERR, referring to the report, said he thought that the proportions in which the subjects had been treated had been altogether lost sight of. The feeding of children had also been somewhat exaggerated in the report. The children that are underfed form a very small residuum. At least that was his own experience, and he thought that it was also the experience of Dr. Chalmers in Glasgow and Dr. Newsholme in Brighton. Underfeeding must be correlated to inefficiency in the parents. As to the question of the Jews, almost unfair use had been made of that argument, because he thought there was such a thing as racial habit of body. At the same time, they found that the Jews lived, flourished and fattened on a diet which English children would not touch. They ate an enormous amount of fat. In his opinion the child in school at once suggests itself as a means of getting hold of a mass of people. We may regard that child as a potential citizen. We also have the other side of the question, the purely educational side, which to a great extent was the view he was compelled to take for practical purposes. Undoubtedly, this class of work must come under the Medical Officer of Health in the future, although he did not think, as far as the educational 
aspect. was concerned, that it would be the best solution. He referred to all those questions of cleanliness, etc., where the school doctor and the sohool nurse come in. The school nurse in London is an efficient person visiting the house, and this personal aspect, as Dr. McVail pointed out, is the new aspect which is opening up in publie health. Each person ought to be taught to make himself fit. The teacher must be taught hygiene and the child must be taught. They wanted to compel them to treat themselves hygienically, and that is the method which is being followed up in London now. Whatever plan is formed the parent is compelled to have it treated so far as the law allows it. He thought it would be generations before the question was properly dealt with, unless the screw was put on in Government quarters. The only way by which it could become general was through the Board of Education, but that Board had been plunging along for generations, apparently without any medical control, although for a small sum this work could be organized throughout the country by a medical department. As to anthropometrical measurements of samples, he thought it would be an excellent plan, but measurements as a general thing throughout the country were not worth the money. They must, however, have samples.

DR. RALPH VINCENT had been impressed by an argument with which he sympathized, and it was that everything should be done to increase the sense of parental responsibility. He wished also that they could do something to increase the sense of responsibility of the House of Commons. He was of opinion that unless they took steps to see that the children were medically inspected no successful results would follow. The question of the feeding of infants was, he considered, a most serious one. In the present state of affairs amongst the working classes the mother could not feed her baby in a natural manner, and the wages of the working man would not allow him to provide a substitute. As to the production of milk, it was a matter which had been absolutely negleeted. Some people wanted to boil it first, others required it sterilized, but Nature intended that it should be consumed without coming into contact with the air. In no other way could they prevent milk from contamination. Consequently, when they proceeded to handle such a dangerous product as that they had to take special measures to meet the case. He considered it very dangerous to give poor people milk, and that sterilized milk should be dispensed with at once. Further, he was of opinion that all municipal milk depots should go by the board. Milk was a most dangerous product to deal with, and no adequate measures had yet been taken to control it.

DR. J. Howakd Jones, referring to the difficulty of moving the Board of Education, said that last year, acting on his advice, his Board passed a resolution that after Jan. 1, 1905, they would not allow children under four years of age to attend school. This was reported to the Educational Department, and the County Council had received a letter from the Board of Education stating that they had no power to exclude children under four years of age. He considered that the efforts of School Education Committees should not be treated in this way by a Government department.

Dr. Francis J. Allan said that he could bear out the statements of Sir John Gorst in regard to the Tower Street school, as he was personally aequainted with it and the methods adopted there. During the last fifteen months they had instituted a Health Society in the City of Westminster, in which they had enlisted the services of district visitors of all creeds. Most of the visitors knew very little about the subject at the commencement of the Society, so that the greater part of the fifteen 
months had been occupied in teaching them. Now that they were becoming used to the work, they were found to be extremely useful. They report directly to a sub-committee for their particular district, and they had found that there were very few whose parents were so destitute that the children could not have sufficient fond, but they did find that they suffered from badly prepared food. Too many parents squander the money in drink they ought to spend on food. They had a very considerable Jewish population, and so far as infants were concerned, the mortality among Jewish babies is very much smaller than it is amongst other nationalities. He had found, however, that when the Jewish children grew up they were quite as susceptible to consumption and zymotic diseases as Christian children appear to be.

Mr. Wolf Derriss, B,A., ventured to express the great satisfaction which be felt in seeing a subject of this kind under the consideration of that Society. The question of physical degeneration had undoubtedly engaged the attention of all those who had taken part in the discussion. They had, no doubt some personal experience, but the one class of man who in the concientious discharge of his duty had inevitably both the maximum of opportunity of observing, and a training second to none in the interpretation of observations of this character, was the Medical Officer of Health. He therefore welcomed the discussion on those grounds.

Dr. C. Sanders desired to place before the meeting the plain facts regarding his authority (West Ham), as Dr. Franklin Parsons had incidentally referred to the borough. The West Ham rates are now 9s. 10d. in the pound; they were 10s. Four years ago the local School Board were coerced by the Education Authority to build a new school, and in order to comply they had to apply to the Local Government Board for funds. The fiat went forth from that body that any municipal trading was to be very seriously checked. Some one whispered that the West Ham rates were $10 \mathrm{~s}$., and West Ham was used as the whipping boy. The Loans Board said that they would not lend. In between these two Government departments his Board were unable to build the schools, but now that the Town Council were the school authority, the foundations were going in. As to Sir Lauder Brunton's paper, he wished to emphasize the necessity of not overlooking parental responsibility. He should be sorry to look forward to the day when the Medical Officers of Health could do without mothers. He could see no reason why the municipal authority should approach the children. He did not see why they should see to them from the time they were born. It is an age of sanitation, and anything that can be labelled sanitation is seized upon by every one nowadays, and he was afraid that sanitation had run to seed. It was a matter of common knowledge that there was a large amount of distress in West Ham. It had undoubtedly been magnified, but fortunately funds were opened, and a huge sum of money was subscribed. A great deal of money just before Christmas was wrongly applied, but there was a balance, and the proposal was to hand it over to the Emigration Society, so that 500 families should be assisted to emigrate. What will be the result? The Emigration Society will come down to West Ham and pick out just the families that I should like to keep there to keep down my death-rate. The good, honest, sober people will be picked out and drafted to the Colonies, and their places filled by the ne'er-do-wells and casuals. This he considered was diametrically opposed to the science of sanitation.

The Presroent (Dr. J. F. J. Sykes) said that the subject was so very wide and the report of the Committee was such an olla podrida that it was 
difficult to deal with it. They had had placed before them by Dr. Franklin Parsons an illustration of how far they were going in assisting the children. Personally he would go a step further, and feed the mothers, for he considered that the evil was in the feeding of the mother. He was disappointed at the insufficient statistical bases in the report of the Committee to found definite opinions upon. To take one illustration, Dr. Tatham supplied the Committee with a very excellent table as to the deaths of children, but the ages of the infants were never extracted. Some years ago the Registrar General did extract the ages of children dying under one year, comparing three agricultural counties with three manufacturing counties. The result was to show that the toll that the manufacturing county took was greater. He, the speaker, had taken two periods and compared the statisties for his borough. He found that exactly the opposite result was taking place to that ascertained by the Registrar-General. For instance, in 1891, as they ran back from the twelfth month the incidence of mortality increased as they advanced towards the mother. The toll was the greater during the first quarter of the life, and apparently the proportion of deaths was increasing at this period. If it was true it meant that the mothers produced the children with less viability. Dr. Tatham pointed out that immaturity was one of the largest causes of the higher mortality amongst infants. Dr. Chalmers had been working at the same thing in Glasgow, and he had got the same results as the speaker. Could we prevail upon Dr. Tatham to have extracted some figures to show if there was any truth in it ? If he could get the same results for all the urban districts, it would be a remarkable result, and would show that there is less viability among the children coming into the world now. That would be due to certain social habits which were creeping into the habits of the mothers. It might also be due to artificial food, but that was not the case in St. Pancras. $\mathrm{He}$ (Dr. Sykes) wished to quote some figures which the Times had published in an incomplete form. The Times compared the mortality of Preston, which all Medical Officers of Health know is where infantile mortality is the highest in the kingdom, and it showed that the deaths from diarrhoea in Preston had fallen enormously, viz. from 197 in 1897 to 103 in 1904. During these two years the earth temperature was exactly the same. He had taken out some figures for other places for the same periods:-

\begin{tabular}{|c|c|c|c|c|c|}
\hline Localities. & & & & $\begin{array}{l}\text { rd Quarter } \\
1897 \text {. }\end{array}$ & $\begin{array}{l}\text { 3rd Quarter } \\
1904 .\end{array}$ \\
\hline Condon & ․ & $\cdots$ & . & & \\
\hline Battersea (Milk Depôt) & $\ldots$ & ... & .. & 243 & 204 \\
\hline Helens $"$, & $\ldots$ & $\ldots$ & ... & 294 & 256 \\
\hline Liverpool & $\ldots$ & $\ldots$ & ... & 329 & 320 \\
\hline Preston (Lady Inspectors) & & $\ldots$ & ... & 449 & 208 \\
\hline
\end{tabular}

Preston does not possess any milk depots, but has women inspectors, while Battersea, St. Helens, and Liverpool have milk depots. These figures, of course may be susceptible of some explanation, and may not bear the interpretation he had put upon them. In addition to feeling sorry that the Committee did not get out the figures referred to, he was equally sorry to see that they recommended all those measures by which the infant could be separated from its mother. Factory work, the institution of milk depots, crêches, in fact every institution which tended to separate parent and child.

StR LAUdER BRUNTON in replying to the discussion said, Dr. Newsholme seemed to think that Sir Frederick Maurice and Sir William Taylor were 
rightly sat upon for having brought forward wrong data, but these data were supplied by the Inspector-General of Recruiting. The data were right enough, but the conclusions drawn from them were inaccurate. They asked for an investigation, and they thought that taken as a whole the records had failed in physical deterioration, and unless he was mistaken, the Committee admitted that they had failed in that direction and said that the reason was not that the whole population had deteriorated, but that they had struck a lower stratum. He considered they had done a great deal of service in drawing attention to the existence of this stiatum. On the question of feeding the school children, there is one country which spends an extremely small amount of money on its army and navy-it has none--but spends an extremely large proportion on education. $\mathrm{He}$ referred to Switzerland, and had made enquiries in Berne on the subject. He found that most of the children attending the schools were fed by the parents, but a small proportion are fed by voluntary aid. A minute proportion are fed by the parishes. The system worked well. He was convinced that the great majority of unfed children might be fed by voluntary committees without much assistance from the rates. The fundamental cause of the evil was summed up in the quotation, "My people perish for lack of knowledge." The lady visitor would do a great deal, but who would instruct the lady visitor? The Medical Officer of Health should instruct her. And who will instruct the teacher ? It is the Medical Officer of Health who will have to look after the playgrounds, the measurement of the children, and upon whom the whole thing falls. Increase the numbers of Medical Officers of Health if necessary; increase his powers; increase certainly his tenure. They could not expect to do away with one of the greatest evils without making his tenure secure. He referred to the question of overcrowding, which is associated with alcoholism. To do away with overcrowding the Medical Officer of Health alone could act, and how could they expect him to do it if he is liable to be turned out of his position because he says that such and such a slum should not be allowed to exist? One of the first things to do was to make sure that a Medical Officer of Health had a proper tenure. Carry out these suggestions, and then "Our people shall no longer perish for lack of knowledge." He asked them to help forward the National League for Physical Education and Improvement. It was still in embryo, but was brought before them as one of the most powerful bodies in the country, and it was for them to see that it was put on right lines. He therefore asked them to pass the following resolution :-

"That the Incorporated Society of Medical Officers of Health expresses its sympathy with the objects of the proposed National League for Physical Education and Improvement, and is prepared to give such advice and assistance in the promotion of the League as may lie in its power."

The bye-laws of the Society having been unanimously suspended, the President put the resolution to the meeting, and declared it to be carried unanimously. A vote of thanks to Sir Lauder Brunton was carried by acclamation. 